\title{
Clinical Trials in Mild Traumatic Brain Injury
}

Michael E. Hoffer, MD FACS ${ }^{1,2,3}$

Mikhaylo Szczupak, MD ${ }^{1,3}$

Carey Balaban, $\mathrm{PhD}^{4}$

1. Department of Otolaryngology, University of Miami Miller School of Medicine

2. Department of Neurological Surgery, University of Miami Miller School of Medicine

3. University of Miami Sports Performance and Wellness Institute

4. Department of Otolaryngology, University of Pittsburgh

\section{Corresponding Author:}

Michael E. Hoffer, MD FACS

Professor of Otolaryngology and Neurological Surgery

University of Miami, Miller School of Medicine

$1120 \mathrm{NW} 14^{\text {th }}$ Street

CRB 5

Miami, FL 33136

(305) 243-1484

Michael.hoffer@miami.edu 


\section{$\underline{\text { Abstract }}$}

Background: Traumatic brain injury is an increasingly prevalent injury seen in both civilian and military populations. Regardless of the mechanisms of injury, the most common sub-type of injury continues to be mild traumatic brain injury. Within the last decade, there has been tremendous growth in the literature regarding this disease entity. Purpose: To describe the obstacles necessary to overcome in performing a rigorous and sound clinical research study investigating mild traumatic brain injury. This examination begins by a consideration of changing standards for good faith open and total reporting of any and all conflicts of interest or commitment. This particularly issue is particularly critical in mTBI research. We next examine obstacles that include but are not limited to diagnostic criteria, inclusion/exclusion criteria, source of injury, previous history of injury, presence of comorbid conditions and proper informed consent of participants. Frequently, multi-center studies are necessary for adequate subject accrual with the added challenges of site coordination, data core management and site specific study conduct. We propose a total reversal to the traditional translational research approach where clinical studies drive new concepts for future basic science studies.

Conclusions: There have been few mild traumatic brain injury clinical trials in the literature with treatments/interventions that have been able to overcome many of these described obstacles. We look forward to the results of current and ongoing clinical mild traumatic brain injury studies providing the tools necessary for the next generation of basic science projects. 


\section{$\underline{\text { Introduction }}$}

Traumatic brain injury is an increasingly common public health issue (Center for Disease Control and Prevention, 2010; Coronado et al., 2012; Defense and Veteran Brain Injury Center, 2015; Harmon et al., 2013; Hendricks et al., 2013; Hoge et al., 2008; Lew et al., 2011; Okie, 2005; Schneiderman et al., 2008; Terrio et al., 2009; Warden, 2006). Every year over 3.8 million individuals in the United States are diagnosed with traumatic brain injury with common causes to include motor vehicle accidents, sports injury, and work related accidents. The situation is even more serious in the military where $20 \%$ of all individuals who have been deployed to Southwest Asia sustain at least one head injury. Head injury/trauma and the resulting sequelae can be stratified into several different classes including mild, moderate, and severe traumatic brain injury. Moderate and severe traumatic brain injury are complex neurological disorders often resulting in invasive procedures and long term specialty care. As a result, these disorders have received significant attention in the literature over time. Mild traumatic brain injury (mTBI), however, is over ten times more common than mild or moderate brain injury yet has not been studied in nearly as much detail (Centers for Disease Control and Prevention, 2010). In this manuscript we will begin by focusing on the obstacles to studying mTBI and then describe the elements of an adequate trial highlighting one recent study with significant outcomes (Hoffer et al., 2010, 2013). We will begin the discussion however with a very important examination of conflict of interest with respect to translational research particularly in regards to mTBI research. 


\section{Conflict of Interest}

The consideration of conflicts of interest for investigators, institutions and private sector sponsors has been a shifting terrain over the past fifteen years. From the perspective of participants, concerns include a financial interest of the researcher (personal income, stock ownership or patent ownership), but may also extend to University patent or investment interests that may be affected by the outcome of study (Kim et al., 2004). The discussion of conflicts of interest in the physician-industry relations area have been broader than strictly the implications of corporate sponsorship of research (Angell et al., 2008; Rothman et al., 2008). From the perspective of academic investigators, there is a strong belief that disclosure of potential conflicts is an acceptable and sufficient tool for management (Glaser et al., 2005; Mecca et al., 2015). The importance of these perceptions may be enhanced by public sensitivity to the concussion problem. Litigation has magnified these issues in relation to claims of potential bias in even peer-reviewed publications about concussion / mTBI. For example, cases regarding claims of concussion reduction systems in football helmets have included public airing of both complaints of over-interpretation and misuse of published results to explicit criticism of interpretation of a published study (Collins et al., 2008) with a participating author from the helmet manufacturer (Case 1:12-cv-20613-PCH https://www.truthinadvertising.org/wp-content/uploads/2014/01/In-Re-RiddellConcussion-Reduction-Litigation-amd-cmpt.pdf Civil Action No. 13-7585 (JBS/JS) United States District Court, D. New Jersey. August 3, 2015. http://www.leagle.com/decision/In\%20FDCO\%2020150805978/In\%20re\%20Riddell\%2 0Concussion\%20Reduction\%20Litigation\#). The very existence of a research 
partnership and co-authorship on a peer-reviewed manuscript can complicate matters if differences of opinions or agendas emerge among the participants. As a result, due diligence in avoiding even the appearance of a conflict of interest seems to be a prudent course of action.

The principle of disclosure of conflict of interest has focused most acutely on the area of significant financial interest. The U.S. Department of Health and Human Services updated its guidelines for financial interest reporting in 2011 (http://grants.nih.gov/grants/policy/coi). This update made conflict of interest reporting more timely but maintained the focus on financial gain as a criterion for conflict of interest. Other organizations, however, have moved toward a broader definition. A National Academy of Sciences (NAS) report proposed that: “A conflict of interest in research exists when the individual has interests in the outcome of the research that may lead to a personal advantage and that might therefore, in actuality or appearance compromise the integrity of the research." This broader definition was motivated by a discussion that was initiated by the NAS own internal study that found that one in five NAS appointed committee members had real financial conflict of interest and an even higher number had conflict of interest by this broader definition (https://www.cspinet.org/new/pdf/nasreport.pdf).

From the perspective of this broader definition, the limited conflict of interest reporting required by NIH, by publishers and by venues hosting speakers is inadequate. Rather, it places an onus on the individual to explain any potential conflict of interest generated by 
intellectual property rights even if the University holds these rights and especially if the value of the intellectual property can be augmented by the study or communication. The issue becomes essentially the provision of sufficient contextual information regarding additional factors (e.g., financial gain, ideological biases or social relationships) that could influence either the conduct of the study or data interpretation. Karenman and colleagues, in Teaching the Responsible Conduct of Research in Humans (RCRH) an update to the 1999 American Academy of Medical Colleges (AAMC), stated that: "A conflict of interest exists when two or more contradictory interests relate to an activity by an individual or an institution. The conflict lies in the situation, not in any behavior or lack of behavior of the individual. That means that a conflict of interest is not intrinsically a bad thing." (http://ori.hhs.gov/education/products/ucla/intro/intro.htm) Hence, comprehensive disclosure has remained a preferred management strategy.

Academic components of research related to mTBI may be supported by pharmaceutical or medical device companies, consortiums of organizations (e.g, sports leagues or federation) and federal entities, including but not limited to the military and the NIH. It is obvious that the corporate sector has a vested interest in the outcome of product-related studies. Conflicts and means of management may be both less obvious and more complex when large organizations fund research in collaboration with corporate and/or government sector sponsors. For example, even the appearance of government favoritism or academic institutional favoritism for a particular corporate entity or product could have significant undesirable consequences. 
In order for mTBI research to go forward we will now examine obstacles and research design concerns. All of these items can be overcome; it remains unclear whether this science and science in general can embrace a new way of reporting conflicts so that the audience truly understands the "situation."

\section{$\underline{\text { Obstacles }}$}

There are a variety of impediments that have plagued both basic science and clinical trial work in mTBI. An objective, consensus definition of mTBI has been an initial challenge for a diagnosis that relies on subjective reports of symptoms. Mild traumatic brain injury has been defined, by default, as traumatic brain injury that is mild, which includes an absence of structural evidence of frank brain injury. However, this definition suffers from boundary issues on both sides. How "severe" does the injury need to be before it crosses from mild to moderate? How "mild" does the injury need to be before it is not an injury at all? And, how is the term "concussion" related to mTBI? Is concussion a synonym, lay terminology, or does it represent a sub category of mTBI? Many investigators have discussed the fact that dividing the disorder into mild, moderate, or severe is a very naïve approach to the injury. These authors point out that there are very few disorders in medicine classified as grossly. While a more appropriate nosology would indeed help make this obstacle less challenging, it still remains to be seen if such a change would not face its own diagnostic challenges. This is in part because there is no accepted gold standard for mTBI diagnosis or injury recovery. As a result, clinical studies are forced to rely on a set of arbitrary inclusion/exclusion criteria and even more vague "recovery" metrics. The investigator must remember that even if they can establish diagnostic 
criteria for mTBI, the issue of precise inclusion and exclusion criteria will still have to be addressed in the absence of a nosology with a strong objective basis. These two factors (definition and inclusion/exclusion criteria) make meta-analysis particularly difficult.

Beyond the difficulty with a definition of mTBI and lack of a "gold standard" for diagnosis of the disorder, mTBI clinical research is complicated by individual differences in response to injury. In general, clinical trials are often affected by individual variations in disease course and manifestations but the variations in mTBI seem to be far greater. This is related to two factors: 1) source and site(s) of the injury and; 2) previous history and physical makeup of the affected individual. Mild traumatic brain injury can be caused by a range of different forces (e.g.. blunt trauma, blast waves, and accelerationdeceleration profiles). Moreover, the incident forces not only vary in type but also have a variety of effects depending on how and where they impact the head. An object of a defined weight traveling at a given speed impacting the anterior aspect of the head (the forehead) is far different than that same object traveling the same speed hitting the lateral aspect (the temple) of the head. Both of these are far different than the impact that occurs in a motor vehicle accident or a fall (Ommaya et al., 2002). These variations are compounded by elements specific to the individual who sustains the impact. Factors such as bone density (literally how hard headed someone is) (Lillie et al., 2016) and neck strength likely have major impacts on overall outcome. The patient-specific issues may be complicated still further by a previous history of multiple, minor impacts. Many individuals who sustain head injuries may have previously diagnosed injuries while others may not even able to identify their previous injuries. The effects of multiple 
injuries can be inferred but remain poorly understood and clearly have an impact on clinical trials.

Closely related to an individual's response to head injury, is the natural clinical course of mTBI. Unfortunately, there are several misconceptions that surround mTBI and these impact mTBI research. The first is that virtually all $\mathrm{mTBI} /$ concussions resolve with no long term symptoms. This belief is not supported by current science. Researchers examining a variety of environments where mTBI symptoms may persists for months to years after even a single injury (Wilk et al., 2012; Tator et al., 2016). Despite the presence of persistent symptoms in individuals with mTBI there is a significant percentage of individuals who do recover. The exact number is not known and depends on both the sensitivity and specificity of the outcome measures as well as the mechanism of injury. This significant rate of spontaneous recovery must be considered when trials are being planned and accounted for in any consideration of study size. The second misconception is that in certain situations (the military in particular) most mTBI symptoms are not secondary to the brain injury but rather are secondary to post-traumatic stress disorder (PTSD) (Marar et al., 2012). A careful analysis of this population will reveal that there are three groups of individuals: 1) those with symptoms secondary solely to PTSD and; 2) those with symptoms secondary solely to mTBI and; 3) those with symptoms secondary to both PTSD and mTBI. In preparing a clinical trial in this population, the presence of these co-morbid conditions needs to be taken into account which can ultimately impact mTBI outcome measures. 
Common to all clinical research trials, there are other obstacles to this type of work which are familiar to this readership. One common issue, informed consent, deserves special attention. Informed consent for brain injury studies is addressed at the level of the local Institution Review Boards, which are the regulatory locus of control. By definition, individuals included in these trials have sustained a brain injury. The question of autonomy, particularly for athletes in organized sports, has been raised (King et al., 2007; King et al., 2013; Robeson et al., 2014), with attempts to extend the Belmont principles to participation in the sport. It is not well understood at what level of injury an individual loses his or her capacity to actually provide informed consent. Thoughtful discussions of the informed consent issue, in particular what determines the ability of an individual to give consent and not give consent must be paramount in study design. It is clear, though, that a discussion with the local institutional review board and any other oversight body is an essential part of designing an appropriate informed consent process for a study.

\section{Elements of mTBI Clinical Trials}

In the absence of a consensus set of objective etiologic diagnostic criteria for mTBI, the subject selection criteria are an essential element of clinical trial related to mTBI. Two strategies have been adopted to address this limitation. The first technique is to be very restrictive in the inclusion criteria for the study. Unfortunately, while perhaps more scientifically sound, this definition may yield inadequate subject recruitment. While this strategy has the potential for success, it usually would need to involve a large potential subject pool spread over multiple institutions. An alternative strategy is to employ a slightly more lenient definition and to later sub-characterize the outcomes. Several 
examples of successfully employing this strategy have been published over the last five years (Boussi-Gross et al., 2013; Hoffer et al., 2013; King et al., 2013; Tator et al., 2016; Wunderle et al., 2014). Confining our search to studies that employ interventions, one can identify a military trial (Hoffer et al., 2013) and a hyperbaric oxygen trial (Tator et al., 2016) that included meaningful subgroup analyses. Perhaps the best examples of employing this strategy are the on-going “TRACK TBI” study (McMahon et al., 2014) and the ongoing NCAA-DoD consortium trial. Both of these studies utilize boarder inclusion criteria; the TRACK TBI study focuses on subjects accrued from the community while the NCAA-DoD trial focuses on college athletes. It should be noted that these studies, as well as a series of new projects beginning in Europe, US high schools and other US college venues must all utilize multiple institutions even given the broader mTBI definition. The only large study to date to utilize a single site was the intheater trial conducted on a population of deployed U.S. Service members (Hoffer et al., 2013). This study was not only unique because it was single site but also since it involved only a very limited set of investigators.

Additional strategies necessary for a successful mTBI study include the selection of methods for assessing outcomes. In mTBI, a disorder with the variety of effects seen, only trials that evaluate a range of neurosensory outcomes can produce the most significant results. Particularly important are a group of neurosensory outcomes including balance function, headaches, cognitive issues, sleep disturbances, hearing issues, and neuropsychiatric comorbidities. It is interesting to note that some studies do examine all of these domains if not more (Boussi-Gross et al., 2013; Hoffer et al., 2013). This is 
particularly true for the ongoing TRACK-TBI and Chronic Effects of Neurotrauma studies. One issue that does come up in examining a large set of outcomes concerns the amount of time required to collect all of the outcome data. This particular issue threatens these studies in two ways. First, long visits for mTBI subjects can result in high study dropout rates or low accrual rates. Second, long visits can result in inaccurate data from mTBI subject fatigue. These factors, as well as the need to find individuals at a particular time point after injury, are an additional reason why larger studies require multiple sites. It is likely moving forward that future mTBI studies will require a multi-center structure to achieve adequate numbers and maximize outcome analysis.

The elements necessary to conduct a good clinical trial on mTBI are the same elements that affect other multi-center studies. These fundamentals include site coordination, data cores, and site study conduct. Examining all the elements that contribute to successful multi-center studies is far beyond the scope of this communication. However, it is important to highlight one of these general aspects with respect to mTBI studies. Foremost is the existing skill set and expertise of the investigator and primary investigative team. Few, if any, other types of clinical trials involve the diverse range of individuals that must be included in mTBI clinical studies. One distinct exception occurred in a unique combat environment which will likely not be seen again (Hoffer $e t$ al., 2013). Current mTBI clinical studies involve neurologists, neuropsychologists, otolaryngologists, ophthalmologists, rehabilitation medicine specialists, physical therapists, and cognitive therapists, just to name a few. Even with these specialists, there will need to be additional help from skilled and talented services in other arenas including 
radiologists, audiologists, speech pathologists, and patient administration representatives. The large number of individuals involved in these studies creates critical issues with respect to study intervention/test timing, protection of patient privacy, patient tracking, and data storage. The organizations conducting the studies we have focused on can overcome these challenges but to do so requires organizational talent and the proper investment of funds/resources.

\section{The Next Generation of Clinical mTBI Studies}

Rapid progress in clinical mTBI studies will require parallel basic research and clinical studies that will transform the area into a field of precision medicine. In brief, the process of studying the disorder and its treatment should also transform the diagnosis from symptomatic and anecdotal classification to an etiologic nosology. Instead of the traditional translational approach in which laboratory developments are subsequently tested in the clinic, we must use the current clinical studies to drive parallel basic science studies, which will provide mechanistic insights and tools to better refine and target the next generation of projects. These concepts can provide more precise biomarkers for the presence of injury or signals of injury resolution. These tools may also provide more novel countermeasures so that we can begin to better study the impact of therapies rather than simply the natural history of the disease. It is also very likely that the tools developed in the field of personalized medicine will need to be employed in mTBI studies as well since mTBI, like many other diseases, does depend on the make-up of the affected individual. 
As we progress through some of the more extensive clinical trials, scientists and clinicians must be focused on the long-term effects of mTBI. Many of the individuals who are affected by this disorder are young. Ignoring the effect of this seemingly mild disorder over time is unwise especially in a pediatric population. Most of the issues that we have discussed earlier become even more difficult with these longer term studies. This group is by definition more heterogeneous; the number of investigators will need to be increased; co-morbidities with other disease processes can cloud outcome measures, and the need for collaboration with other institutions is likely even more significant. Although challenging, these longitudinal studies may have the most important impact of any studies in the field of mTBI research.

\section{Conclusion}

This communication is unusual for this journal because it focuses on the issues of conducting the science rather than the science itself. This is not intended to be an exhaustive discussion of issues with regards to clinical research but rather focused on some of the most challenging problems with respect to mTBI studies. As we have seen, the current generation of projects are large multi-institutional studies focused on the natural history of mTBI as much as anything else. We look forward to these works informing basic scientists so that they can help develop the next generation of studies many of which, hopefully, will focus on countermeasures and treatment.

\section{Funding:}

This work was supported by Head Health Challenge II grant (National Football League, Underarmor, General Electric) and Department of Defense grant W81XWH-12-C-0205. 


\section{$\underline{\text { References }}$}

1. Angell M. Industry-sponsored clinical research. JAMA 2008; 300: 1069-1071.

2. Boussi-Gross R, Golan H, Fishlev G, Bechor Y, Volkov O, Bergan J, et al. Hyperbaric oxygen therapy can improve post concussion syndrome years after mild traumatic brain injury - randomized prospective trial. PLoS One 2013;8:e79995. doi: 10.1371/journal.pone.0079995.

3. Collins M, Lovell MR, Iverson GL, Ide T, Maroon J. Examining concussion rates and return to play in high school football players wearing newer model helmet technology: a three-year prospective cohort study. Neurosurgery 2008;58:275286.

4. Coronado VG, McGuire LC, Sarmiento K, Bell J, Lionberger MR, Jones CD, et al. Trends in Brain Injury in the U.S. and the public health response: 1995-2009. J Safety Res 2012;43:299-307. doi: 10.1016/j.jsr.2012.08.011.

5. Centers for Disease Control and Prevention, Traumatic Brain Injury in the United States: Emergency Department Visits, Hospitalizations and Deaths 2002-2006. http://www.cdc.gov/traumaticbraininjury/pdf/blue_book.pdf, 2010 (accessed 03.07.2016).

6. Defense and Veterans Brain Injury Center, DoD Worlwide Numbers for TBI. http://dvbic.dcoe.mil/dod-worldwide-numbers-tbi, 2015 (accessed 03.07.2016).

7. Glaser BE, Bero LA Attitudes of academic and clinical researchers toward financial ties in research: a systematic review. Science and Engineering Ethics 2005; 11:553-573; 
8. Harmon KG, Drezner JA, Gammons M, Guskiewicz KM, Halstead M, Herring SA, et al. American Medical Society for Sports Medicine position statement: concussion in sport. Br J Sports Med 2013;47:15-26. doi: 10.1136/bjsports-2012091941.

9. Hendricks AM, Amara J, Baker E, Charns MP, Gardner JA, Iverson KM, et al. Screening for mild traumatic brain injury in OEF-OIF deployed US military: an empirical assessment of VHA’s expereince. Brain Inj 2013;27:125-34. doi: 10.3109/02699052.2012.729284.

10. Hoffer ME, Balaban C, Gottshall K, Balough BJ, Maddox MR, Penta JR. Blast exposure: vestibular consequences and associated characteristics. Otol Neurotol 2010;31:232-6. doi: 10.1097/MAO.0b013e3181c993c3.

11. Hoffer ME, Balaban C, Slade MD, Tsao JW, Hoffer B. Amelioration of acute sequelae of blast induced mild traumatic brain injury by $\mathrm{N}$-acetyl cysteine: a double-blind, placebo controlled study. PLoS One 2013;8:e54163. doi: 10.1371/journal.pone.0054163.

12. Hoge CW, McGurk D, Thomas JL, Cox AL, Engel CC, Castro CA. Mild traumatic brain injury in U.S. Soldiers returning from Iraq. N Engl J Med 2008;358:453-63. doi: 10.1056/NEJMoa072972.

13. King NMP, Robeson R Athlete or guinea pig? Sports and enhancement research. Studies in Ethics, Law, and Technology, 2007.

14. King NMP, Robeson R Athletes are guinea pigs. The American Journal of Bioethics, 2013, 13:18-28. 
15. King EG, Kretzmer TS, Vanderploeg RD, Asmussen SB, Clement VL, Belanger HG. Pilot of a novel intervention for postconcussive symptoms in active duty, veterans, and civilians. Rehabil Psychol 2013;58:272-9. doi: 10.1037/a0033116.

16. Kim SYK, Millard RW, Nisbet P, Cox C, Caine ED. Potential research participants' views regarding researcher and institutional financial conflicts of interest. J Medical Ethics 2004; 30: 73-79.

17. Lew HL, Pogoda TK, Baker E, Stolzmann KL, Meterko M, Cifu DX, et al. Prevalence of dual sensory impairment and its association with traumatic brain injury and blast exposure in OEF/OIF veterans. J Head Trauma Rehabil 2011;26:489-96. doi: 10.1097/HTR.0b013e318204e54b.

18. Lillie EM, Urban JE, Lynch SK, Weaver AA, Stitzel JD. Evaluation of Skull Cortical Thickness Changes with Age and Sex from Computed Tomography Scans. J Bone Miner Res 2016;31:299-307. doi: 10.1002/jbmr.2613.

19. Marar M, McIlvain NM, Fields SK, Comstock RD. Epidemiology of concussions among United States high school athletes in 20 sports. Am J Sports Med 2012;40:747-55. doi: 10.1177/0363546511435626.

20. Mecca JT, Gibson C, Giorgini V, Medeiros KE, Mumford MD, Connelly S. Researcher perspectives on conflict of interest: a qualitative analysis of views from academia. Science and Engineering Ethics 2015; 21:843-855

21. McMahon P, Hricik A, Yue JK, Puccio AM, Inoue T, Lingsma HF, et al. Symptomatology and functional outcome in mild traumatic brain injury: results from the prospective TRACK-TBI study. J Neurotrauma 2014;31:26-33. doi:10.1089/neu.2013.2984. 
22. Ommaya AK, Goldsmith W, Thibault L. Biomechanics and neuropathology of adult and paediatric head injury. Br J Neurosurg 2002;16:220-42.

23. Okie S. Traumatic brain injury in the war zone. N Engl J Med 2005;352:2043-7.

24. Robeson R, King NMP. Loss of possession: concussions, informed consent, and sutonomy. 2014 Journal of Law, Medicine \& Ethics; 334-343.

25. Rothman DJ, Chimonas S. New developments in managing physician-industry relationships. JAMA 2008; 300: 1067-1069.

26. Schneiderman AI, Braver ER, Kang HK. Understanding sequelae of injury mechanisms and mild traumatic brain injury incurred during the conflicts in Iraq and Afghanistan: persistent postconcussive symptoms and posttraumatic stress disorder. Am J Epidemiol 2008;167:1446-52. doi: 10.1093/aje/kwn068.

27. Tator CH, Davis HS, Dufort PA, Tartaglia MC, Davis KD, Ebraheem A, et al. Postconcussion syndrome: demographics and predictors in 221 patients. $\mathbf{J}$ Neurosurg 2016:1-11.

28. Terrio H, Brenner LA, Ivins BJ, Cho JM, Helmick K, Schwab K, et al. Traumatic brain injury screening: preliminary findings in a US Army Brigade Combat Team. J Head Trauma Rehabil 2009;24:14-23. doi: 10.1097/HTR.0b013e31819581d8.

29. Warden D. Military TBI during the Iraq and Afghanistan wars. J Head Trauma Rehabil 2006;21:398-402.

30. Wilk JE, Herrell RK, Wynn GH, Riviere LA, Hoge CW. Mild traumatic brain injury (concussion), posttraumatic stress disorder, and depression in U.S. soldiers involved in combat deployments: association with postdeployment symptoms. Psychosom Med 2012;74:249-57. doi: 10.1097/PSY.0b013e318244c604. 
31. Wunderle K, Hoeger KM, Wasserman E, Bazarian JJ. Menstrual phase as predictor of outcome after mild traumatic brain injury in women. J Head Trauma Rehabil 2014;29:E1-8. doi: 10.1097/HTR.0000000000000006. 